\title{
НА ПУТИ К НОВОЙ ЕДИНОЙ ЕВРОПЕ: ПОЗИЦИЯ ХРИСТИАНСКИХ ЦЕРКВЕЙ НА ВЫБОРАХ В ЕВРОПАРЛАМЕНТ 2019 г.
}

Аннотация. В статье проанализирована роль христианских иерквей в преддверии выборов в Европарламент (ЕП) 2019 г. В рамках предвыборной борьбы за места в ЕП ярче всего проявилась двойственная и внешне противоречивая позищия христианских иерквей. Во-первых, иерковные структуры всячески отстаивают иелостность и интересы Евросоюза (ЕС), объединения, которое отказалось упоминать в своей Конституции, а затем и в Лиссабонском договоре, свои христианские корни. Помимо этого, руководство ЕС выступает с секулярных либеральных позиций, которые часто ограничивают верующих в их желании проявлять свою веру в публичном пространстве или же защищать свои интересы и иенности, нарушая политкорректность (называть однополье союзы грехом, носить религиозные символы где угодно и т.д.). Во-вторых, прямо или косвенно христианские иеркви осуждают активистов правых партий, которые, наоборот, скорее поддерживают исторические ичеркви, говорят об утраченной роли христианства в Европе, о необходимости вернуться к традициям и христианской идентичности. Проповедь большинства христианских иерквей уже давно приобрела глобальный характер, по сути, миссия уже не может быть не направлена и на работу среди иммигрантов и беженцев. При этом, за редким исключением, представители иеркви не запрещают верующим голосовать за правые партии, которые поднимают столь важные для иерквей вопросы европейского будущего.

Ключевые слова: миграция, межрелигиозный диалог, христианство, протестантизм, православие, католицизм, государственно-иерковные отношения.

Призывы христианских церквей накануне выборов в Европарламент 2019 г. демонстрируют тот накал политических дискуссий, который существует в целом вокруг противостояния традиционных партий и партий «политической альтернативы» ${ }^{1}$. Опасность изменения соотношения сил в ЕП в пользу «правых популистов», которых правильнее по существу называть альтернативными силами, заставила церкви и межцерковные объединения (католиков, протестантов, православных) вмешаться в выборный процесс и занять более или менее определённую позицию.

Одной из ключевых особенностей церковно-политической точки зрения является формальное стремление не вмешиваться в политику и не поддерживать ни одну из партий, хотя совершенно очевидно против кого направлен вектор церковных призывов - против партий

\footnotetext{
(с) Лункин Роман Николаевич - кандидат философских наук, доктор политических наук, ведущий научный сотрудник, руководитель Центра по изучению проблем религии и общества Отдела социальных и политических исследований ИЕ РАН, главный редактор журнала «Современная Европа». Aдрес: 125009, Россия, Москва, Моховая ул., д. 11, стр. 3. E-mail: romanlunkin@gmail.com.
}

DOI: http://dx.doi.org/10.15211/vestnikieran22019155162

${ }^{1}$ Партии и движения политической альтернативы в современной Европе. Сб. статей. Отв. ред. В.Я. Швейцер. М., ИЕ РАН, 2018. С. 36-53. 
политической альтернативы или, по крайней мере, против наиболее радикальных представителей этих партий. В рамках предвыборной борьбы за места в Европарламенте ярче всего проявилась двойственная и внешне противоречивая позиция христианских церквей. Дело в том, что заявления церквей и церковных лидеров могут привести к выводу, что они действуют исключительно себе во вред. Во-первых, церковные структуры всячески отстаивают целостность и интересы Евросоюза, объединения, которое отказалось упоминать в своей Конституции, а затем и в Лиссабонском договоре, свои христианские корни. Помимо этого, руководство ЕС выступает с секулярных либеральных позиций, которые часто ограничивают верующих в их желании проявлять свою веру в публичном пространстве или же защищать свои интересы и ценности, нарушая политкорректность (называть однополые союзы грехом, носить религиозные символы где угодно и т.д.). Во-вторых, прямо или косвенно христианские церкви осуждают активистов правых партий, которые, наоборот, скорее поддерживают исторические церкви, говорят об утраченной роли христианства в Европе, о необходимости вернуться к традициям и христианской идентичности.

Политическая коллизия, в которую попали церкви Европы, требует особого внимания, поскольку помогает более глубоко понять церковное мировоззрение и почему церкви не готовы поддерживать своих «друзей» и защищают своих «врагов». Возникает целый ряд вопросов: почему и как происходит формирование политической стратегии церквей, является ли это для них самих коллизией и может ли подобное поведение церковных объединений нанести вред их политическому значению, или же наоборот его увеличит в перспективе?

Прежде всего, необходимо отметить, что у сотрудничества церквей и европейских институтов, в том числе и Европарламента, есть твёрдое правовое основание. Таковым является ст. 17 Лиссабонского договора, которая была одобрена абсолютным большинством религиозных объединений Евросоюза. Статья предписывает поддерживать открытый и регулярный диалог между институтами ЕС и церквями, религиозными объединениями, философскими и неконфессиональными организациями. В 2017 г. председатель ЕП Антонио Таяни утвердил своего заместителя Мэйрид МакГиннесс в качестве ответственной за ведение этого диалога. Как и на уровне Еврокомиссии, в Европарламенте регулярно проводятся семинары, конференции и консультации с религиозными лидерами по вопросам прав человека, миграции, защиты христиан на Ближнем Востоке. Проводится семинар «Диалога вокруг статьи 17» на тему «Будущее Европы: рефлексии для ЕС 2025». Антонио Траяни отмечал в ходе такого семинара, что диалог с церквями и другими движениями - это возможность быть ближе к гражданам, которые избрали депутатов. По мнению МакГиннесс, церкви и религиозные группы являются частью повседневной реальной жизни, частью общинной жизни городов и деревень. Помимо этого, церкви своим опытом и богословием могут способствовать тому, что человеческое достоинство будет в центре принятия решений в $\mathrm{EC}^{1}$.

Следует отметить, что в рамках Европарламента есть два разнонаправленных вектора. Один направлен за строгое отделение церкви от власти - в рамках ЕП действует Рабочая группа по отделению религии от государства. Другой - поддерживает традиционалистские ценности и частично опирается на религиозный электорат, как, к примеру, электорат Европейской народной партии (ЕНП) и группы Европейских консерваторов и реформистов, частью которых является Европейское христианское движение политическое (ЕСРМ) ${ }^{2}$. Семинар, по-

\footnotetext{
${ }^{1}$ Religious and non-confessional dialogue. URL: http://www.europarl.europa.eu/at-your-service/en/be-heard/religiousand-non-confessional-dialogue.

2 European party unites Christians all over Europe: «We are stronger together». Orbán, Mariska - Katholiek Nieuwsblad. 26.02.2019. URL: https://cruxnow.com/church-in-europe/2019/02/26/european-party-unites-christians-allover-europe-we-are-stronger-together/
}

Научно-аналитический вестник ИЕ РАН, 2019, №2 
священный беженцам из Сирии, был организован Рабочей группой по межкультурному диалогу ЕНП, а также ключевыми церковными объединениями, которые сотрудничают с институтами ЕС на наднациональном уровне. Это Конференция европейских церквей (CЕС), Комиссия Конференции католических епископов ЕС (СОМЕСЕ) и Комитет представителей православных церквей ЕC (CROCEU) ${ }^{1}$. Исследователи, проводившие опросы депутатов Европарламента, отмечали относительность влияния церквей или христианского мировоззрения на политиков, которое либо минимально, либо опосредовано ${ }^{2}$. Помимо этого, вследствие отсутствия религиозной политики и законодательства на уровне ЕС, церкви сталкиваются с серьёзной проблемой. С одной стороны, это растущая необходимость оправдать установленное место, традиционно занимаемое различными типами национальной, государственной или доминирующей церкви. С другой стороны, развитие наднационального законодательства, где ацент делается на общих и единых основных правах граждан. Церквям всё труднее оправдать своё автоматическое право на уникальные политические привилегии, такие как государственное финансирование или юридические исключения, особенно в областях политики, касающихся образования и занятости, где законодательство ЕС стремится обеспечить равные возможности. Исследователи делают вывод, что общепринятая модель церковно-государственных отношений становится периферийной для $\mathrm{EC}^{3}$. С этой точки зрения, вполне понятным становится стремление церквей заявить свою позицию, но при этом не дискредитировать себя - ни отрицанием прав и свобод человека, ни связью с радикальными националистами.

Основной темой заявлений церковных объединений накануне выборов в Европарламент стала забота о беженцах и обо всех иммигрантах. Отношение к иммиграции стало в значительной степени ёмкой политической повесткой дня, которая смогла вместить в себя массу других вопросов, важных для церквей. Это и милосердие, и терпимость как следование христианским заповедям, и в целом стремление увидеть в будущих решениях ЕС христианскую мотивацию. Во многом церкви стараются убедить в этом и самих европейцев, к которым они обращаются.

Конференция европейских церквей совместно с Комиссией церквей по делам мигрантов в Европе издала специальную памятку по церковной активности во время выборов в Европарламент под названием «Европа: это наше будущее». Приветствуя участие верующих в демократическом процессе, церкви отмечают, что разделяют такие ценности ЕС как справедливость, мир, солидарность, примирение, толерантность и человеческое достоинство и будут работать вместе ради гуманной и социально ориентированной Европы. В памятке также отмечается, что «глобальный экономический кризис, экономические столкновения и безработица, приток беженцев и рост национализма драматически изменили жизнь современной Европы». Однако церкви поддерживают европейский проект, стремятся строить мосты, выступают против изоляции. В разделе «Будущее ЕС» прямо отмечается опасность популизма и политического экстремизма и необходимость выдерживать курс на Евросоюз как «сообщество общих ценностей». В разделе «Европейская социальная модель и будущее труда» выражается поддержка инклюзивной политике и развитию справедливых условий труда для всех. В том числе, подчёркивается необходимость защиты частной и семейной жизни и времени от требова-

\footnotetext{
1 A path towards the resilience of Syrian people. 05.04.2019. Press Release No: 19/07. Brussels. URL: http://www.ceceurope.org/a-path-towards-the-resilience-of-syrian-people/

2 Foret, François. "“Religion at the European Parliament": purposes, scope and limits of a survey on the religious beliefs of MEPs», Religion, State \& Society. 42/2-3, 2014. P. 108-129.

${ }^{3}$ Religion and Secularism in the European Union. Université libre de Bruxelles Observatory of Religions and Secularism (ORELA) Report September 2018 Caroline Sägesser Jan Nelis Jean-Philippe Schreiber Cécile Vanderpelen-Diagre. URL: http://www.o-re-la.org/index.php/analyses/item/2359-religion-and-secularism-in-the-european-union?tmpl=com ponent \&print=1.
} 
ний цифровизации и плавающего рабочего графика. По поводу миграции церкви придерживаются общей позиции, которая транслируется ими уже на протяжении нескольких лет. В частности, в памятке указано: «иммигранты и беженцы из разных стран приезжают, чтобы строить новую жизнь в европейском доме. Хотя и есть вызовы, с этим связанные, иммигранты вносят свой вклад в экономическое процветание Европы и обогащают её уже и так разнообразные общества». Программа церквей включает в себя также проблемы изменения климата и устойчивое развитие, помощь развивающимся странам, заботу о том, чтобы экономическое процветание сочеталось с социальной и экологической ответственностью. Стремление к Европе равенства и инклюзивной политики, по мнению, церквей, включает в себя права человека и свободу религии, борьбу против любых форм дискриминации и гендерное равенство. Главная задача общецерковного документа - побудить граждан участвовать в формировании европейского проекта, изучать позиции своих кандидатов и точку зрения своих же церквей ${ }^{1}$. К такого рода действиям верующих призвали представители 114 церквей (православных, протестантов, англикан), которые входят в Конференцию европейских церквей.

Целый ряд церквей и христианских организаций выступили по существу с пацифистских позиций. Это проявилось в двух документах, которые издало экуменическое сообщество «ерковь и мир» и Экуменическая консультация за справедливость и мир. Первый текст содержит вопросник, с помощью которого предполагается проверять позиции кандидатов по следующим темам: 1) субсидирование военной отрасли; 2) усиление не военного, ненасильственного решения и предупреждения конфликтов; 3) экспорт европейского вооружения; 4) иммиграция и предоставление убежища ${ }^{2}$. Второй документ касается спасения «Европейского мирного проекта» и призывает ЕС отказаться от военного сотрудничества с третьими странами и больше вкладывать в ненасильственное разрешение и управление конфликтами ${ }^{3}$. Девиз проекта - «За мир, за права человека, за Европу». Авторы документов, обращённых к кандидатам в Европарламент, отмечают, что Европа стала моделью мира для всех, когда европейская интеграция примирила врагов после Второй мировой войны. Однако в настоящее время мирная политика пала жертвой защиты от иммигрантов, и с 2021 г. ЕС планирует вложить миллиарды евро в вооружение, военные операции и укрепление своих границ. В рамках документа «Спасём Европейский мирный проект» прямо указывается, что на ненасильственное разрешение конфликтов и миротворчество необходимо 7 млрд евро, а на продвижение прав человека и демократию необходимо 3 млрд евро в 2021-2027 гг. финансовом периоде. В связи с предполагаемыми военными тратами ЕС сторонники инициативы опасаются, что парламент и страны - члены ЕС могут поддаться давлению со стороны правых популистов и вложить намного больше в выстраивание границ и обеспечение полицейской безопасности. Документ «Спасём Европейский мирный проект» подписали 74 различных организации из 9 стран Европы, в том числе «Гринпис» и сеть «Церковь и мир». В основном, среди тех, кто поддерживает антивоенные призывы к Европарламенту, традиционно пацифистские протестантские конфессии, такие как меннониты, квакеры, такая либеральная конфессия как методисты, некоторые евангелисты и лютеране, братство англикан-пацифистов.

Сдержанностью и философской основательностью отличается Заявление Конференции

\footnotetext{
${ }^{1}$ Europe: it's our future. A tool for Church action in the 2019 European Parliament elections from the Conference of European Churches and Churches' Commission for migrants in Europe. URL: http://www.ceceurope.org/wpcontent/uploads/2019/03/CEC_eu-election_EN_8.pdf.

${ }_{2}^{2}$ Position checklist for the election to the European Parliament 23-26 May 2019. URL: https://www.church-andpeace.org/en/2019/02/position-checklist-for-the-election-to-the-european-parliament-23-26-may-2019/

PRESS RELEASE For peace. For human rights. For Europe. 74 organisations call for the rescue of the European peace project. 02.02.2019. URL: http://www.ceceurope.org/wp-content/uploads/2019/02/PR_SavetheEuropeanPeace Project_04022019.pdf.
}

Научно-аналитический вестник ИЕ РАН, 2019, №2 
католических епископов Европы (СОМЕСЕ) по поводу предстоящих европейских выборов 2019 г. Епископы напоминают будущим членам Европарламента, что Католическая церковь уже на протяжении двух тысяч лет является часть европейской конструкции. Общее настроение перед лицом существующих вызовов иерархи называют менее оптимистичным, чем во времена заключения Лиссабонского договора. При этом современный этап Католическая церковь считает наилучшим для перезапуска европейского проекта, потому что «ЕС несовершенен и скорее всего нуждается в новом образе (нарративе) надежды, который сможет вовлечь граждан в проекты, которые станут более инклюзивными и будут лучше служить общему благу». Ключевыми понятиями для ЕС должны стать вновь обретённая идентичность, солидарность, субсидиарность, в том числе основанные на активизации диалога церквей и институтов ЕС. Как и другие межцерковные объединения, Конференция католических епископов затронула в своём заявлении вызовы цифровизации, социальной рыночной экономики, семейной политики. В отношении иммиграции и миграции епископы также призвали изменить походы ЕС и взглянуть на проблему шире: «Интеграция является проблемой не только для тех, кто приезжает в ЕС, но и для тех, кто переезжает из одной страны в другую внутри ЕС... Кроме того, миграция и предоставление убежище это не какие-то независимые темы, они тесно связаны с солидарностью, с вниманием к человеку, эффективной экономической и демографической политикой». Одно из пожеланий епископов звучит так: «Европа должна оставаться конкурентоспособной, не отказываясь от своих принципов и стандартов» 1 . Безусловно, епископы не могли обойти стороной и размышления папы Франциска в 2017 г. «Переосмысляя Европу», в рамках которых папа пожелал Европе не терять надежду и обновиться, отвечая на нужды и ожидания граждан, очевидно, и тех, кто является членами церкви, которая вот уже две тысячи лет периодически меняет европейскую конструкцию. Католицизм, безусловно, стремится стать важной частью европейского проекта будущего.

Целый ряд церковных и околоцерковных организаций не только активно поддержали евроинтеграцию, но и резко выступили против национализма и всех «антиевропейских» сил. К примеру, Координационная группа по религии и образованию в Европе, объединяющая целый ряд общеевропейских союзов учителей, представителей церквей, в своём обращении по поводу выборов прямо отмечает, что единство Европы ещё никогда не было в такой опасности. Кроме того, брекзит и политическая атмосфера растущего национализма поставили под угрозу европейский проект. Среди требований группы: противостояние антиевропейским голосам и силам, приверженность общим ценностям уважения к человеческому достоинству, демократии, равенству и т.д., которые следуют также из «традиции авраамических религий». Своё обращение группа заключает словами: «Надеемся, мы больше не увидим национализм снова!» ${ }^{2}$.

Конференция церквей на Рейне выпустила своё обращение по теме «Европа и выборы», также сделав тревожное заявление: «Реалии и ценности, которые на нашем континенте воспринимались как должное - мир, демократия, социальная и экологическая справедливость, права человека - ставятся под сомнение. Церкви, которые внесли значительный вклад в поддержку этих ценностей в последние десятилетия, не могут оставаться в стороне от дискуссии». Помимо этого, церкви предложили 6 тезисов о будущем Европы по числу 6 недель Великого поста для молитвенных размышлений: 1. Созидание мира; 2. Европа солидарности и равных возможностей; 3. Европа и изменение климата; 4. Индивидуальные свободы в противовес

\footnotetext{
${ }^{1}$ REBUILDING COMMUNITY IN EUROPE COMECE Bishops' Statement in view of the 2019 European Elections. URL: http://www.ceceurope.org/wp-content/uploads/2019/02/2019-02-12_Election_Statement.pdf.

${ }^{2}$ CoGREE Appeal to take part in the European elections in May 2019 and to support educational activities for a peaceful and sustainable Europe. URL: https://cogree.org/2019/02/28/cogree-appeal-european-election/
}

Научно-аналитический вестник ИЕ РАН, 2019, №2 
экономической и политической власти; 5. Европа разнообразия и плюрализма; 6. Усиление государства права и партиципаторной демократии, борьба с авторитаризмом ${ }^{1}$. В бюллетене Конференции говорится о том, что необходимо усилить Европу в духе Христа, в том числе защищая права беженцев и борясь с любыми формами расизма и национализма. По воскресеньям предполагается посвятить проповеди с библейскими чтениями следующим темам: разрешение конфликтов гражданским действием, сделать мир справедливым и начать с Европы, увеличение личной свободы против экономической и политической власти, Европа будущего разнообразна и красочна, усиление роли права и субсидиарности. Все эти молитвенные призывы были поддержаны Союзом протестантских церквей Эльзаса и Лотарингии, Евангелической церковью Бадена, Евангелической церковью Пфальца, которые и образуют Конференцию церквей на Рейне (в конфессиональном отношении они принадлежат к лютеранам и реформатам $)^{2}$.

Голосовать на выборах в Европарламент призвал также Комитет представителей православных церквей ЕС, состоящий из членов Вселенского патриархата, Московского патриархата, патриархатов Румынии, Болгарии, церквей Кипра и Греции. Православные выделили три главных направления: воспитание молодого поколения в духе единой европейской идентичности как граждан демократического общества, общая ответственность за приём беженцев среди стран ЕC, политика сохранения окружающей среды как Божьего творения на основе инновационной сберегающей экономики. В отношении иммиграционной проблемы православные призвали смотреть более широко: «необходимо более глубокое осмысление проблемы, основанное на более последовательной и дальновидной политике соседства и внешних действий» ${ }^{3}$.

Следует отметить, что католическая и православная церкви прямо не упоминали про популистские партии в своих заявлениях и не говорили об угрозе национализма. Исторические церкви не хотят терять свой традиционный электорат или, по крайней мере, его часть, которая голосует за правых. Православные церкви и так немногочисленны в рамках всего ЕС по сравнению с католиками и протестантами, а избиратели в Болгарии или Румынии, Греции явно настроены более в русле правых популистов. Что касается католиков, то они в значительной степени ослаблены скандалами вокруг педофилии духовенства, что подрывает доверие к Церкви у тех, кто мог бы ей симпатизировать, будучи правым и традиционалистом.

Участие церковных институтов (церквей, их объединений на наднациональном уровне - мноконфессиональных и межцерковных) в политической жизни Европы становится всё более заметным на фоне использования религиозной риторики правыми популистами, прямого отношения к официальной позиции церквей не имеющим. Водораздел между требованиями популистов и интересами церквей проходит в понимании ими идентичности. Для христианских церквей идентичность в сохранении религиозных традиций, а для многих популистов, даже упоминающих христианскую веру, как имеющую значение, идентичность состоит скорее в сохранении «того, что есть», суверенитета, самобытности своей страны, культуры, городка или деревни. Для церкви же важно заменить антииммигрантскую или любую враждебную идентичность на ревность о вере, на возрождение христианской веры. И в этом христианском идеализме, как часто это бывало в истории, есть очень большая доля прагматизма.

\footnotetext{
${ }^{1}$ Élections européennes 2019: une déclaration des Églises riveraines du Rhin Façonner l'avenir de l'Europe ! Un encouragement des Églises riveraines du Rhin. URL: http://acteurs.uepal.fr/public_files/file/texte_de_reflexion.pdf.

2 Conference of the Churches on the Rhine CCR newsletter. March-April 2019, 01/2019. URL: http://www. ceceurope.org/wp-content/uploads/2019/03/KKR_Info_EN_01_03-04.2019.pdf.

${ }_{3}$ Committee of Representatives of the Orthodox Churches to the European Union. Statement of Croceu. In view of the European elections May 2019. URL: http://www.ceceurope.org/wp-content/uploads/2019/04/European-Elections-20191.pdf.
}

Научно-аналитический вестник ИЕ РАН, 2019, №2 
Волна агрессивности по отношению к иммигрантам вполне может пройти и оставит церкви ни с чем, с тем же секуляризованным населением. Замкнутость в своих границах и самобытности ограничиться столь же секулярной культурой с фольклорными элементами, в конце концов, поставит заслон на христианской миссии. Тогда как проповедь большинства христианских церквей уже давно приобрела глобальный характер, по сути, миссия уже не может быть не направлена и на работу среди иммигрантов и беженцев. При этом, за редким исключением, представители церкви не запрещают верующим голосовать за правые партии, которые поднимают столь важные для церквей вопросы европейского будущего.

\section{Список литературы}

Европа XXI века. Новые вызовы и риски. Под общей ред. Ал.А. Громыко, В.П. Фёдорова. М., СПб., Нестор-История, 2017. 584 с. Серия: Старый Свет - новые времена. С. 100-122.

Лункин Р.Н. Миссия милосердия: социальное служение церквей. Современная Европа, №4(70), 2016. С. 154-158.

Митрофанова А.В. Социальная работа православных некоммерческих организаций: направления, цели, типология. Гуманитарные науки. Вестник Финансового университета, №1, 2013. C. 32-43.

Партии и движения политической альтернативы в современной Европе. Сб. статей. Отв. ред. В.Я. Швейцер. М., ИЕ РАН, 2018. С. 36-53.

Религиозные миссии на общественной арене: российский и зарубежный опыт. Колл. моногр. Под ред. А.А. Красикова и Р.Н. Лункина. Центр по изучению проблем религии и о-ва ИЕ РАН. М., ИЕ РАН, 2016.

Современная Италия: старые проблемы, новые вызовы. Отв. ред. Е.А. Маслова. М., ИЕ PAH, 2018. C. 79-91.

Mapping migration, mapping churches' responses in Europe: Belonging, Community, and Integration: the Witness and Service of Churches in Europe. Churches' Commission for Migrants in Europe. 2016. URL: http://www.ccme.be/fileadmin/filer/ccme/70_DOWNLOADS/20_Publications /2016-01-08-Mapping_Migration_2015_Online__lo-res__2_.pdf.

\section{References}

Evropa XXI veka. Novye vyzovy i riski. Pod obschei red. Al.A. Gromyko, V.P. Fyodorova. M., SPb., Nestor-Istoriya, 2017. 584 s. Seriya: Staryj Svet - novye vremena. S. 100-122.

Foret, François «"Religion at the European Parliament”: purposes, scope and limits of a survey on the religious beliefs of MEPs», Religion, State \& Society. 42/2-3, 2014. P. 108-129.

Lunkin R.N. Missiya miloserdiya: social'noe sluzhenie cerkvej. Sovremennaya Evropa, №4(70), 2016. S. 154-158.

Mitrofanova A.V. Social'naya rabota pravoslavnyh nekommercheskih organizacij: napravleniya, celi, tipologiya. Gumanitarnye nauki. Vestnik Finansovogo universiteta, №1, 2013. S. 32-43.

Partii i dvizheniya politicheskoj al'ternativy v sovremennoj Evrope. Sb. statej. Otv. red. V.Ya. Shvejcer. M., IE RAN, 2018. S. 36-53.

Religion and Secularism in the European Union. Université libre de Bruxelles Observatory of Religions and Secularism (ORELA) Report September 2018 Caroline Sägesser Jan Nelis Jean-Philippe Schreiber Cécile Vanderpelen-Diagre. URL: http://www.o-re-la.org/index.php/analyses/item/ 2359-religion-and-secularism-in-the-european-union?tmpl=component\&print=1. 
Religioznye missii na obshchestvennoj arene: rossijskij i zarubezhnyj opyt. Koll. monogr. Pod red. A.A. Krasikova i R.N. Lunkina. Centr po izucheniyu problem religii i o-va IE RAN. M.,IE RAN, 2016.

Sovremennaya Italiya: starye problemy, novye vyzovy. Otv. red. E.A. Maslova. M., IE RAN, 2018. S. 79-91.

\section{On the way to the New United Europe: the Position of the Christian Churches During the Elections to Europarliament 2019}

Author. Roman Lunkin, Candidate of Sciences (Philosophy), Senior Fellow, the Head of the Center for Religious Studies, Institute of Europe, Russian Academy of Sciences, deputy editor-inchief of the journal «Contemporary Europe». Address: 11-3, Mokhovaya str., Moscow, Russia, 125009. E-mail: romanlunkin@gmail.com.

Abstract. In the article analyzed the role of the Christian Churches before the elections to the Europarliament 2019. During the elections became evident the ambivalent the formally contradictive position of the churches. At first the churches stand for the values and interests of the EU that refused to mention its Christian roots in the Constitution and then in the Lisbon Treaty. Besides that the EU leadership has secular liberal positions that often limited believers in their attempts to express their faith in public sphere. Secondly, directly or not Christian churches blame the activists of the right wing parties that more likely support the historical churches saying on the returning to Christian roots and the past role of the Christianity in Europe. In that conditions the mission of the majority of the Christian churches has a global character and also inevitably touches immigrants and refugees. With the rare exclusion the church leadership didn't prohibit for the believers to vote for the right wing parties that raising so important for the churches questions.

Key words: migration, interreligious dialogue, Christianity, Protestantism, Orthodoxy, Catholicism, Church-State relations.

DOI: http://dx.doi.org/10.15211/vestnikieran22019155162 